\title{
Study of The Influence of Chromium on A Cobalt Iron Alloy
}

smain mebrek ( $\nabla$ s.mebrek@crti.dz)

Centre de Recherche en Technologies Industrielles

mourad zergoug

Centre de Recherche en Technologies Industrielles

nacereddine haine

Universite des Sciences et de la Technologie Houari Boumediene

Original Article

Keywords: Fe-Co powder, Mechanical alloying, Magnetic properties, Microwave

Posted Date: May 28th, 2020

DOI: https://doi.org/10.21203/rs.3.rs-30234/v1

License: (1) This work is licensed under a Creative Commons Attribution 4.0 International License.

Read Full License 


\section{Abstract}

The present work comes within the framework of research of new materials, with improved properties, which could be an important key for innovative applications.

For this purpose, two types of alloys, a binary ( $\mathrm{Fe}, \mathrm{Co}$ ) and a ternary ( $\mathrm{Fe}, \mathrm{Co}, \mathrm{Cr}$ ), were first synthesized by mechanical grinding at high energy, varying the grinding time.

In a second step, all the samples were subjected to various characterizations, a structural study (X-ray diffraction), a morphological study (scanning electron microscopy "SEM"), a magnetic characterization (the "VSM" vibrating sample magnetometer And finally, an electrical study (eddy currents).

Numerous and valuable information was then deduced to know the variations in the average lens size, the internal micro deformation, the cell parameter, the saturation magnetization, the remnant field, the coercive field as well as the $\mathrm{Z}$ impedance, according to a only parameter, the grinding time.

\section{Introduction}

The study of magnetic materials is the basis of the extraordinary development recorded at the end of the nineteenth century. All recent research converges on the transition to a nanoscale in which the properties of these materials are significantly improved over those known.

We chose the mechanical grinding method; inexpensive and easy to implement for solid state materials, without melting and by grinding various basic elements in the form of powders.

The Fe-Co system is initially the focus of our attention because it is the basis of permanent magnets, which can be obtained in a wide range. We are also interested in a ternary $\mathrm{Fe}-\mathrm{Co}-\mathrm{Cr}$ system, with the aim of improving the properties for some specific applications of these.

The structural behavior will be studied as a function of the grinding time by analyzing the graphs obtained and from the average lens size, the internal microdeformations, as well as the parameter of the cell.

Finally, we will pay particular attention to the magnetic behavior of these nano-alloys which will be studied according to different grinding times. From the obtained magnetization curves, we will determine the most relevant magnetic quantities, such as the coercive field $\mathrm{Hc}$, the remanent induction and the saturation moment. These characteristics will make it possible to evaluate the magnetic behavior of these nano-alloys.

\section{Materials And Methods}

The basic elements, namely iron, cobalt and chromium initially were the subject of a weighing in a highprecision analytical balance. Note that the starting powders were of high purity; namely for $99 \%$ iron, 
$99.8 \%$ cobalt and $99.5 \%$ chromium.

For our study, we used a Fritish Pulverisette 7 type planetary mill, consisting of two jars that rotate around a vertical axis (its own axis), in the opposite direction of the rotational movement animating the plate (disk) that carries it.

Choosing a mass of $2.25 \mathrm{G}$ for binary and ternary one, we were brought to prepare alloys whose nominal compositions are of the $\mathrm{Fe}_{65} \mathrm{Co}_{35}$ type for the binary one and $\left(\mathrm{Fe}_{65} \mathrm{CO}_{35}\right)_{90} \mathrm{Cr}_{10}$ for the ternary one. Is result from it that the two types of alloys of the mixture differ by the percentage of each component (Fe, $\mathrm{Co}$ and $\mathrm{Cr}$ ) with respect to the total weight of the sample and this, as follows:

\begin{tabular}{|ll|}
\hline Fe65Co35 & (Fe65Co35)90Cr10 \\
\hline $\mathrm{Fe}=1.4625 \mathrm{~g}$ & $\mathrm{Fe}=1.31625 \mathrm{~g}$ \\
\hline $\mathrm{Co}=0.79 \mathrm{~g}$ & $\mathrm{Co}=0.70875 \mathrm{~g}$ \\
$\mathrm{Cr}=0.0 \mathrm{~g}$ & $\mathrm{Cr}=0.225 \mathrm{~g}$ \\
\hline
\end{tabular}

In order to obtain a homogeneous distribution of the starting elements, we carried out a manual mixing in a mortar during 10 min. the mixture of powders obtained was introduced into the two jars, each containing six stainless steel balls, sealed with a lid provided with a Teflon ring seal which makes it possible to maintain the tightness of the jar during grinding and avoids the contact between the outside atmosphere and the powder during the grinding operation.

The grindings were carried out at different times: $0,1.3,6,8,12,24$ and $36 \mathrm{~h}$; in order to prevent any excessive rise in the temperature inside the jars, grinding is interrupted for 15 minutes every half hour of grinding.

For a better characterization of our samples, we used several techniques to know diffraction of $x$-rays (DRX), magnetometry with vibrating sample (VSM) and the eddy currents.

\section{Results And Discussion}

\subsection{STRUCTURAL STUDY}

The use of adequate ASTM data sheets allowed the indexing of all existing lines, in particular revealing $\mathrm{Fe}(\mathrm{CC}), \mathrm{Co}(\mathrm{HC}), \mathrm{Co}(\mathrm{CFC})$ and $\mathrm{Cr}(\mathrm{CC})$, in addition to phases binary $(\mathrm{Fe}, \mathrm{Co})$ and ternary $(\mathrm{Fe}, \mathrm{Co}, \mathrm{Cr})$, all the two cubic ones centered.

These graphs characterize the structural and the quantitative evaluation of each of these elements.

One can easily admit that that the primary action of grinding is to introduce a rather violent plastic deformation which is necessarily accompanied by a high population of specific defects, linear and plans, 
whose respective movements are likely to change a number of characteristics of the systems studied, like the average size of crystalline, internal micro deformations or the cell parameter.

At first approximation, the highlighting of this state of affairs is related to the height and the width at half height of the different diffraction peaks obtained the first decreasing and the second increasing with the grinding time.

Moreover, it appears that the CFC phase of the Co disappears in the binary ( $\mathrm{Fe}, \mathrm{Co})$ after 1 hour of grinding, while it does not even exist in the ternary alloy ( $\mathrm{Fe}, \mathrm{Co}, \mathrm{Cr})$.

On the other hand, for the same grinding time, the compact hexagonal phase of Co remains present in two alloys, this is probably due to the fact that the CFC phase of Co is metastable at ambient temperature, becomes unstable and is transformed finally into $\mathrm{HC}$ [1].

In addition, the compact hexagonal phase of the Co completely disappears from the two alloys, dice 8 hours of grinding.

Concerning the alloy $\left(\mathrm{Fe}_{65} \mathrm{Co}_{35}\right)_{90} \mathrm{Cr}_{10}$, it appears that only the solid solution ( $\mathrm{Fe}, \mathrm{Co}, \mathrm{Cr}$ ) remains present from 6 hours of grinding. The formation process of the ternary alloy is thus started until its finalization with time.

\subsection{VARIATIONS IN THE AVERAGE SIZE OF CRYSTALLITES}

Two theoretical methods have been used, that of Williamson-Hall and that of Scherrer [2; 3].

It first appears that the average size of crystalline is a function that decreases with time.

The curve for the binary alloy (Fe $\mathrm{Co}$ ) can be approximated by a negative straight line, implying that it is at the high grinding times that the difference between the two methods fades. Concerning the ternary $\left(\mathrm{Fe}_{65} \mathrm{CO}_{35}\right)_{90} \mathrm{Cr}_{10}$, the shape of variation as a function of the grinding time is more random. It seems that the smallest gap appears from the first hour of grinding and then, slightly increases, before almost stabilizing. The effect of $\mathrm{Cr}$ most probably is part of this evolution.

\subsection{EVOLUTION OF THE CRYSTALLINE PARAMETER}

The variations of the crystalline parameter as a function of the grinding time, for the two types of sample, $\mathrm{Fe}_{65} \mathrm{Co}_{35}$ and $\left(\mathrm{Fe}_{65} \mathrm{Co}_{35}\right)_{90} \mathrm{Cr}_{10}$, are shown in Figs. 5 and 6 .

These graphs can be divided into four parts, a decrease of a between 0 and 1 hour of grinding, an increase of up to 6 hours of grinding, a second decrease of up to 12 hours of grinding and finally an increase of up to 36 hours of grinding.

Moreover, the reduction phase of the parameter a, for the two alloys, can have different origins. Indeed, concerning the binary $\mathrm{Fe}_{65} \mathrm{CO}_{35}$, the decay of a can be explained by the possible substitution of $\mathrm{Fe}$ atoms 
by those of the Co in the sub-network Fe, and also by the formation of defects (gaps, dislocations, grain boundaries) [4-5].

Recall that the atomic radius of Co is significantly lower than that of Fe. Between 12 and 36 hours of milling, the increase in "a" is attributed to the migration of Co atoms out of the Fe sub-network, towards the grain boundaries. However, for the ternary $\left(\mathrm{Fe}_{65} \mathrm{Co}_{35}\right)_{90} \mathrm{Cr}_{10}$, the increase of "a" could be understood by a divisional competition between $\mathrm{Co}$ and $\mathrm{Cr}$, in the sub-network $\mathrm{Fe}$, it being understood that the diffusion coefficient of $\mathrm{Co}$ is by far, superior to that of $\mathrm{Cr}[5,6]$.

More generally, the process of decreasing the average crystallite size is the product of a competition between the generation of dislocations created by the grinding process and the crystallization dynamics of the materials, due to the local increase in temperature [7].

\subsection{MAGNETIC PROPERTIES}

The starting point of any study of magnetic properties of a material is the determination of the hysteresis cycle associated with it, under the operating conditions chosen. It is indeed from this graph that all the important parameters are extracted, such as the remnant field $\mathrm{Br}$, the saturation magnetization $\mathrm{BS}$ or the coercive field Hc. Figures 7 and 8 shows the evolution of the magnetization of the samples as a function of the applied magnetic field for different grinding times.

The coercivity $\mathrm{Hc}$ is often considered as an important parameter because it strongly contributes to the identification of the magnetic nature of the material. A high value of $\mathrm{Hc}$ indicates the existence of microdeformations, impurities and various defects that occur during the grinding operation [8].

In Fig. 9, it appears that between 0 and 8 hours of grinding, the behavior of his is quite erratic, in that for $\mathrm{Fe}_{65} \mathrm{CO}_{35}$, it decreases, grows and decrease successively, while for and $\left(\mathrm{Fe}_{65} \mathrm{Co}_{35}\right)_{90} \mathrm{Cr}_{10}$, it is the opposite phenomenon which appears, a decrease followed by an increase.

This last result is quite comparable to that found by S. Khosravi et al [1]. It is admitted that the drop of Hc during the first crushing times is attributed to the decrease of the volume fraction of $\mathrm{Co}$, when it passes from the cubic phase with centered faces (CFC) to compact hexagonal cell (HC).

Indeed, the H.C structures are known to have a higher magneto-crystalline anisotropy than those that are CFC [9]; however, graph analysis shows the progressive disappearance of compact hexagonal Co in favor of face-centered cubic Co, hence the behavior of his.

On the other hand, the fact that his increases between 8 and 24 hours of grinding, in the binary and ternary alloys, could be related to an accumulation of defects and to a greater contamination, with regard to the duration of the grinding which is higher. For a grinding time greater than 24 hours, Hc decreases due to other phenomena. Machine et al [10] showed that his decreases rapidly with decreasing mean crystalline size when the domain wall is larger than the size of the crystalline. In addition, during this grinding period, the particles change shape from a lamellar to a spherical shape, thus leading to the 
reduction of shape-related anisotropy. Moreover, the variations of saturation magnetization bias as a function of time are shown in Fig. 10.

It can first be noted that the values of Bs, for the two samples, behave differently, so the addition of $\mathrm{Cr}$ appears to be disturbing. Moreover, contrary to the results of the literature [11], Bs is not constant in the case of $\mathrm{Fe}_{65} \mathrm{Co}_{35}$. In our case, $\mathrm{Bs}$ is sensitive to the microstructural changes of the material, ie the defects of all kinds that appear and their movement, especially at the beginning of grinding.

In a second step, the decrease in the average size of the crystalline, associated with a possible modification of their shape, from lamellar to spheroidal, induces a loss of anisotropy, therefore an increase of Bs. This trend is likely to be reinforced by the increase of the crystalline parameter and the finalization of the process of synthesis of the product.

The presence of $\mathrm{Cr}$ which is antimagnetic in the ternary explains the decrease of Bs; hence the total magnetic moment is affected by a modification of the configuration between neighboring atoms; therefore, and assuming that $\mathrm{Fe}$ and $\mathrm{Co}$ are ferromagnetic, the presence of $\mathrm{Cr}$ in their immediate environment will cause a sharp fall in Bs.

Starting from the observation that $\mathrm{Br}$ and $\mathrm{BS}$ behave in the same way, a cross analysis of all the results shows that the values of $\mathrm{Br}$ and $\mathrm{BS}$ are relatively high, implying that $\mathrm{Fe}_{65} \mathrm{Co}_{35}$ and $\left(\mathrm{Fe}_{65} \mathrm{Co}_{35}\right)_{90} \mathrm{Cr}_{10}$ has a magnetic energy from 12 hours of grinding, the binary alloy seems to form and reach a form of stability; this is due to the disappearance of cobalt. Moreover, the fact that $\mathrm{Hc}$ admits high values suggests a possible use of this alloy in the magnetic discs.

The addition of chromium in the ternary disturbs the formation of the alloy, which is made from 12 hours of grinding; this is characterized by instability observed during this period and is particularly evident in the variations of the remanent field Br.finally, over a long time, Hc remains almost constant, with a similar evolution to that observed in binary; nevertheless $\mathrm{Hc}$ is magnified around 24 hours, this confirms the influence of chromium and therefore accredits the idea of the magnetic hardness of the ternary studied.

\subsection{EDDY CURRENT}

For the binary, we note in the first, the curves $Z=f(t)$, obtained for the two frequencies, confirm the results obtained by DRX and VSM. Indeed, as soon as the 12 hours of grinding, Z admits a quasi-constant, this result is to connect with $\mathrm{Hc}$ and with the appropriate curve of DRX. It has been mentioned above that this remarkable point corresponds to the beginning of the formation of the alloy, before stabilizing.

Note that a second remarkable point, corresponding to $t=8$ hours, is also to be noted; some authors claim that it corresponds to a metallurgical instability, materialized here by a magnetic polarization [11].

For the ternary alloy, quite comparable results were obtained, as regards the beginning of the formation of the alloy and its stability whatever the frequency considered. 
Here again, for $t=8$ hours, the same metallurgical instability seems to occur, it is attributed to the fact that a magnetic polarization, due to the spin orientation of the different constituents, is responsible for this situation [11].

Since the behavior of the ternary alloy, in Foucault currents for the two frequencies, are comparable, this implies the need to use frequencies low enough to interpret the metallurgical state of the powder, because the choice of the latter depends essentially the depth of the sample to be controlled, which is inversely proportional to the square root of the frequency [12].

It should be noted, moreover, that from 12 hours of crushing, the action of $\mathrm{Cr}$ becomes predominant. This is, indeed, materialized by a high value of $Z$, which corresponds to a higher hardness.

Based on the literature of systems that resemble ours, it is argued that these results are important and the non-destructive testing of eddy current samples can diagnose the nanostructural state. In addition, the scattering in the impedance curves is probably due to the poor compactness of the samples as well as to the existing porosity [11].

\section{Conclusion}

The potential application of alloys $\left(\mathrm{Fe}_{65} \mathrm{CO}_{35}\right)$ and $\left(\mathrm{Fe}_{65} \mathrm{Co}_{35}\right){ }_{90} \mathrm{Cr}_{10}$ was the main motivation of our choice. At first, we synthesized our products using a high energy mechanical grinder and varying the grinding time. In a second step, we characterized our samples by adopting multiple techniques, such as X-ray Diffraction, Scanning Electron Microscopy, eddy currents and vibrating sample magnetometry. The curves of DRX show that the effect of the grinding time is undeniable. Indeed, for the binary, the alloy is formed at 12 hours of grinding, followed by a stability range related to the gradual disappearance of Co.

Regarding the ternary, it seems that the addition of $\mathrm{Cr}$ disrupts the formation of the alloy that appears at grinding times greater than $12 \mathrm{~h}$.

This is well shown by the study of the evolution of the remaining field, $\mathrm{Br}$. The study of the magnetic properties reveals the values of residual field, $\mathrm{Br}$, and of saturation magnetization, $\mathrm{BS}$, high for the binary, implying the existence of an appreciable magnetic energy.

The presence of $\mathrm{Cr}$ in the ternary amplifies the maximum value of $\mathrm{Hc}$, although maintaining a shape of the curve $\mathrm{Hc}=\mathrm{f}(\mathrm{t})$, similar to that obtained in the case of the binary. This situation appears around $t=$ $24 \mathrm{~h}$ and has the consequence of making the ternary more magnetically harder than the binary.

Regarding the binary alloy, the first remark that can be made is that the curves, $Z=f(t)$, obtained for the two frequencies, confirm the results obtained by DRX and VSM, a beginning of formation of the alloys at 12 and 8 hours of grinding, respectively, followed by stabilization, It should be noted that from 12 hours of grinding, the action of $\mathrm{Cr}$ becomes predominant.

\section{Declarations}




\section{Authors' Contributions}

S.mebrek was in charge of the whole trial; wrote the manuscript; M.zergoug and N.haine assisted with sampling and laboratory analyses; All authors provided necessary help during the process of analyses and approved the fnal manuscript.

\section{Author Details}

1 Research Center In Industrial Technologies -CRTI-, P.O.Box 64,Cheraga 16014 Algiers, Algeria.

2 .The University of Science and Technology Houari Boumedienne- USTHB, P.O.Box 32, El Alia, Bab Ezzouar, 16111, Algiers, Algeria.

\section{Competing Interests}

The authors declare that they have no competing interests.

\section{Acknowledgements}

I sincerely thank Professors M.Zergoug of CRTI and N.Haine of USTHB for their critical discussions and reading during manuscript preparation.

\section{Funding}

The authors declare that they have no funding; we used CRTI products and USTHB analysis machines.

\section{Ethics approval and consent to participate}

Not applicable.

\section{Availability of data and materials}

Data are available from the authors upon reasonable request and with permission of [S.Mebrek].

\section{References}

1. Khosravi,S., Alizadeh,M., Sharafi,S., Karimi-Maleh, H., Atar,N. (2015). Structural,magnetic and electron transfer effect of $\mathrm{Cr}$ additive on $\mathrm{Fe}_{65} \mathrm{CO}_{35}$ nanopowder fabricated mechanical alloying. Powder Technology, 279, 262-268.

2. Gravereau, P. (2011). Introduction à la pratique de la diffraction des rayons $X$ par les poudres (Doctoral dissertation, Sciences Chimiques).

3. Courleux, A. (2011). Physico-chimie des échanges matrice/renfort dans un matériau composite acier/TiC (Doctoral dissertation, Université Claude Bernard-Lyon I). 
4. Chermahini, M. D., Sharafi, S., Shokrollahi, H., Zandrahimi, M., \& Shafyei, A. (2009). The evolution of heating rate on the microstructural and magnetic properties of milled nanostructured Fe $1-\mathrm{x}$ Co x ( $\mathrm{x}$ $=0.2,0.3,0.4,0.5$ and 0.7$)$ powders. Journal of Alloys and Compounds, 484(1), 54-58.

5. Schaffer, G. B., \& McCormick, P. G. (1990). Displacement reactions during mechanical alloying. Metallurgical Transactions A, 21(10), 2789-2794.

6. Bhattachaya, A. K., \& Arzt, E. (1992). Diffusive Reaction During Mechanical Alloying of Intermetalics. Scripta Metall. Mater, 27, 635-639.

7. Chen, C. W. (2013). Magnetism and metallurgy of soft magnetic materials. Courier Corporation.

8. Shokrollahi, H. (2009). The magnetic and structural properties of the most important alloys of iron produced by mechanical alloying. Materials \& Design,30(9), 3374-3387.

9. Alleg, S., Azzaza, S., Bensalem, R., Suñol, J. J., Khene, S., \& Fillion, G. (2009). Magnetic and structural studies of mechanically alloyed (Fe $50 \mathrm{Co} 50) 62 \mathrm{Nb} 8 \mathrm{~B} 30$ powder mixtures. Journal of Alloys and Compounds, 482(1), 86-89.

10. McHenry, M. E., Willard, M. A., \& Laughlin, D. E. (1999). Amorphous and nanocrystalline materials for applications as soft magnets. Progress in Materials Science, 44(4), 291-433.

11. Yousefi, M., \& Sharafi, S. (2012). The effect of simultaneous addition of Si and Co on microstructure and magnetic properties of nanostructured iron prepared by mechanical alloying. Materials \& Design, $37,325-333$.

12. Zergoug, M., Oubouchou, H., \& Haddad, A. (2008). Détermination des nano structure par les méthodesmagnétiques. In Cofrend-Congrès Toulouse 2008.

13. Mohn, P. (2006) Magnétisme à l'état solide: une introduction (Vol 134.).Springer Science \& Business Media.

\section{Figures}



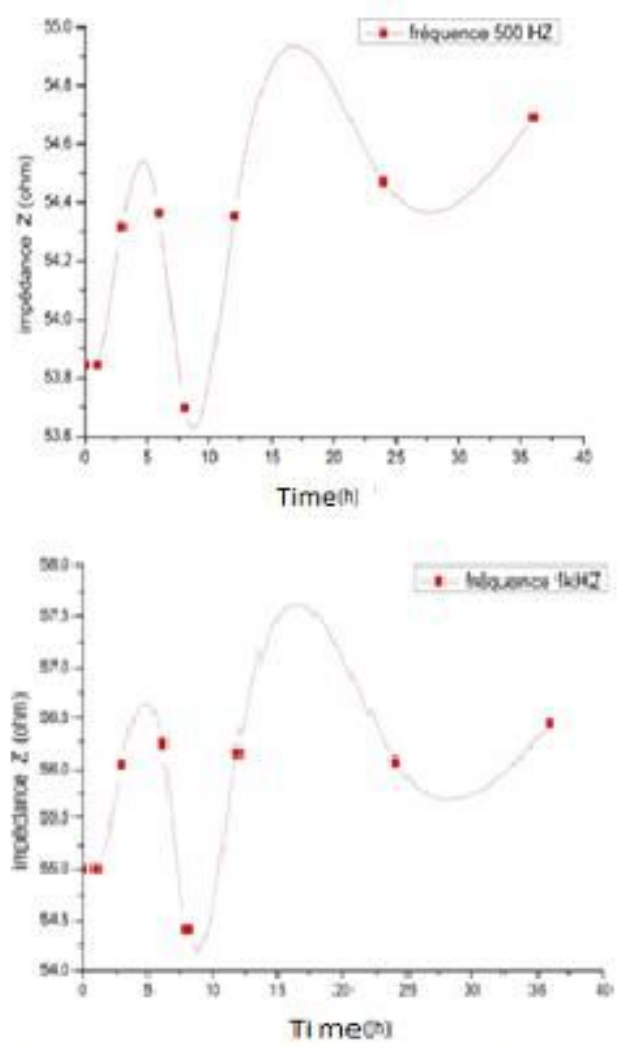

Fig12. Variations of the impedance $\mathrm{Z}$ for $\mathrm{Fe}_{65} \mathrm{Co}_{35}$

\section{Figure 1}

Figure 12
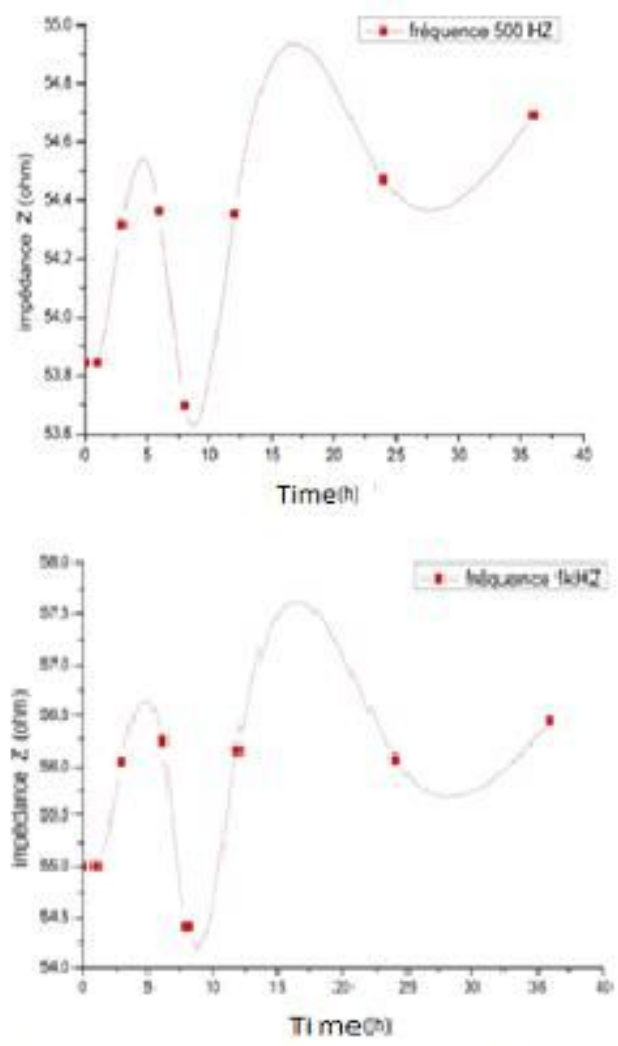

Fig12. Variations of the impedance $\mathrm{Z}$ for $\mathrm{Fe}_{65} \mathrm{Co}_{35}$ 
Figure 2

Figure 1 Figure 2

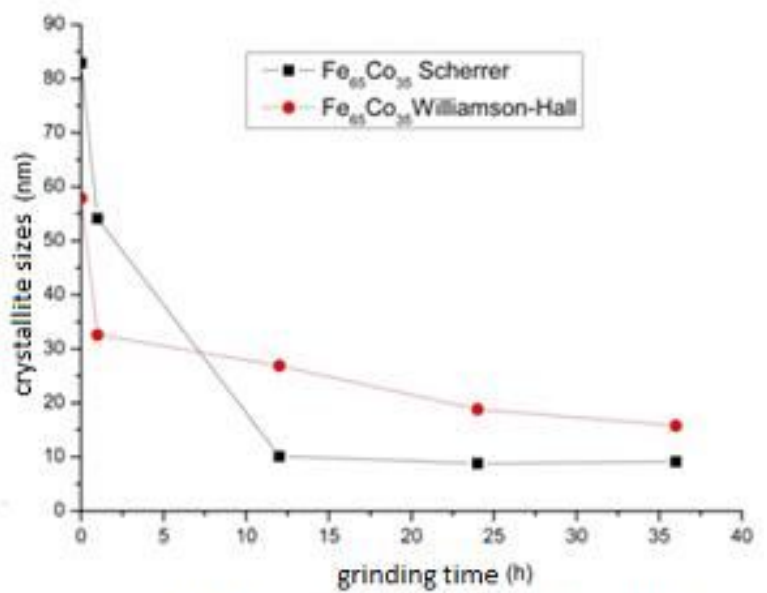

Fig. 3 Evolution of the average crystallite

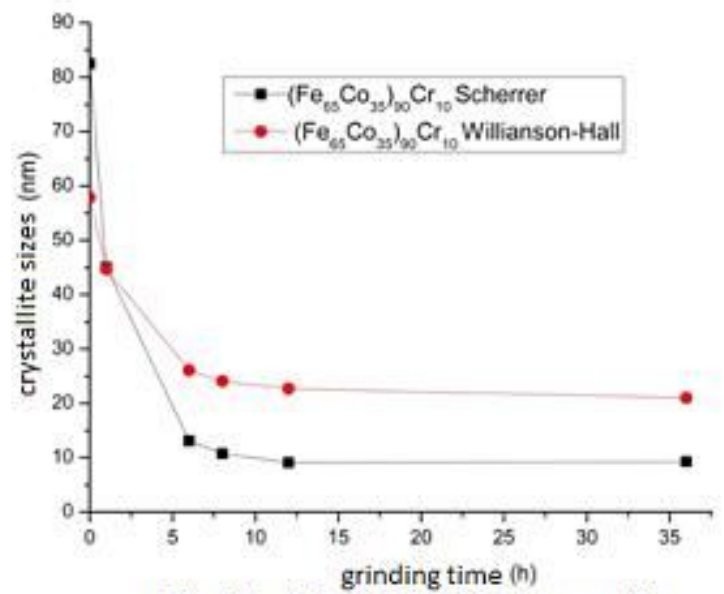

Fig.4 Evolution of the average crystallite

\section{Figure 3}

Figure 3 Figure 4 


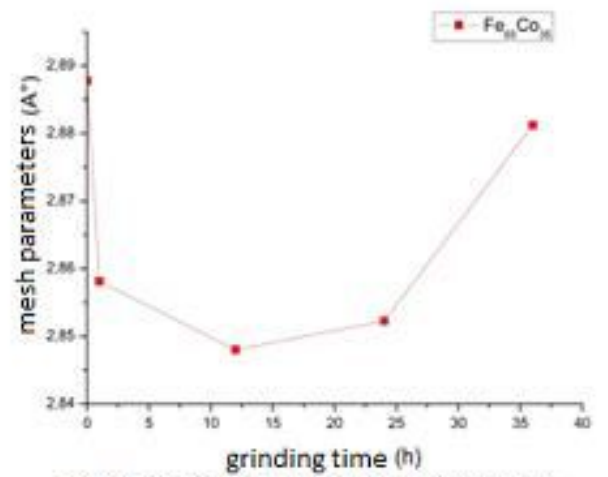

Fig.5 Evolution of the mesh parameter

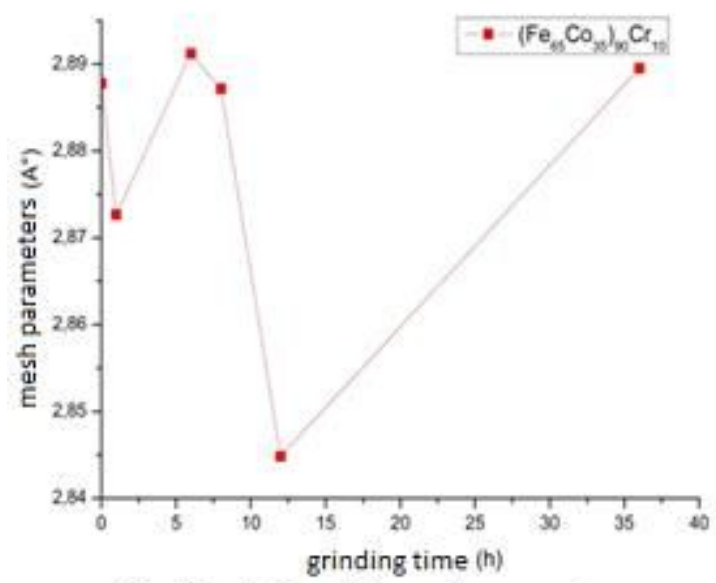

Fig.6 Evolution of the mesh parameter

Figure 4

Figure 4 Figure 6 

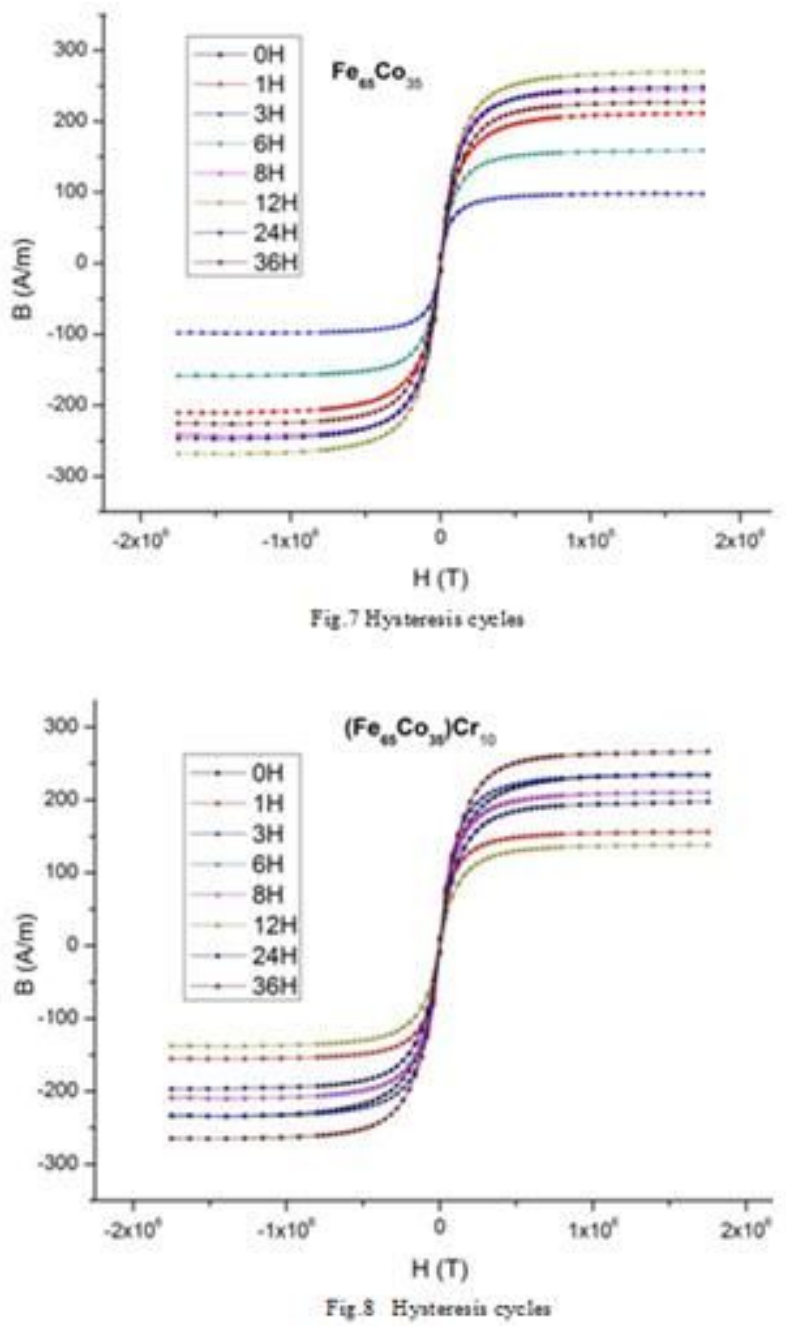

\section{Figure 5}

Figure 7 Figure 8

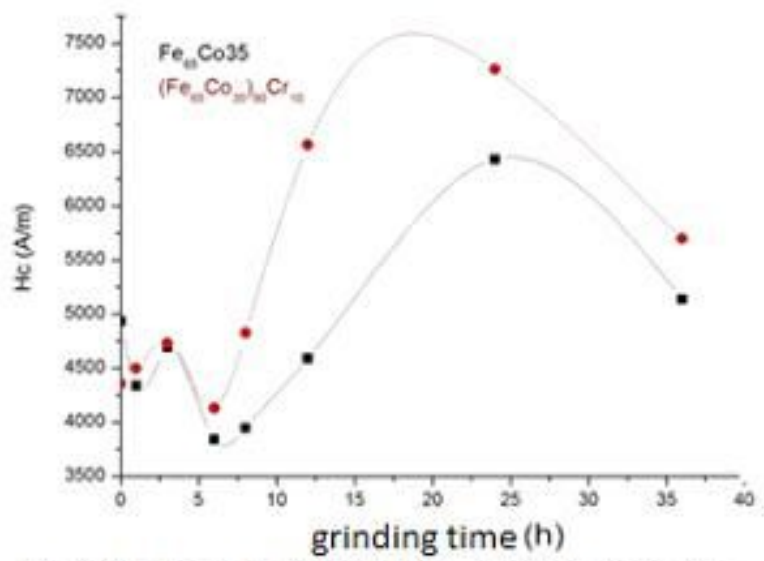

Fig. 9 Variations of $\mathrm{Hc}$, for $\mathrm{Fe}_{63} \mathrm{C}_{35}$ and $\left(\mathrm{Fe}_{63} \mathrm{C}_{035}\right)_{90} \mathrm{Cr}_{30}$

\section{Figure 6}

Figure 9 


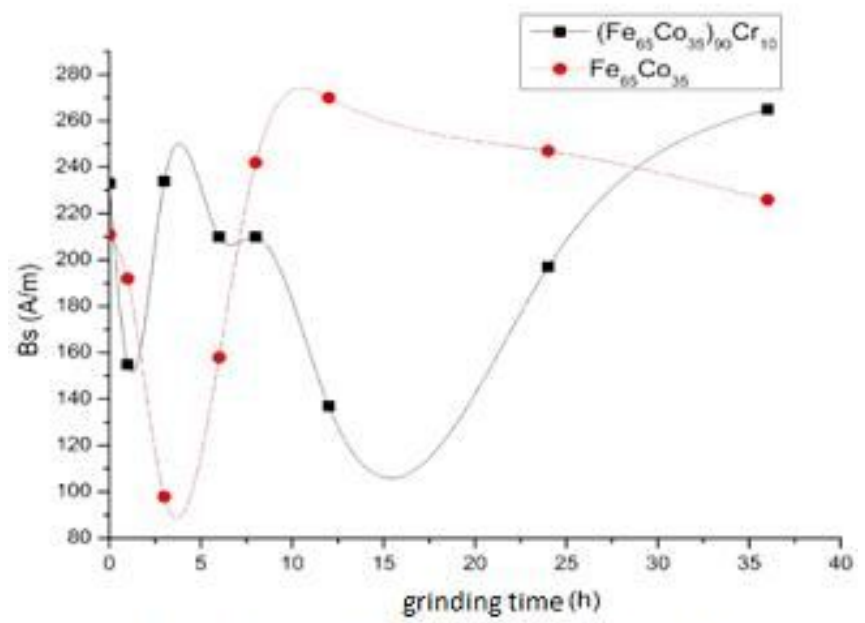

Fig. 10 Variations of saturation magne tization Bs

\section{Figure 7}

Figure 10

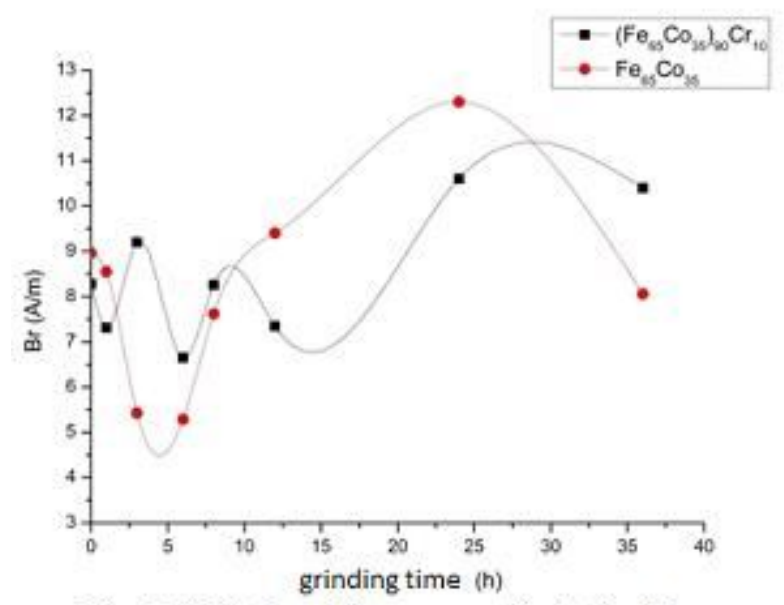

Fig.11 Variations of the remanent induction $\mathrm{Br}$

Figure 8

Figure 11 

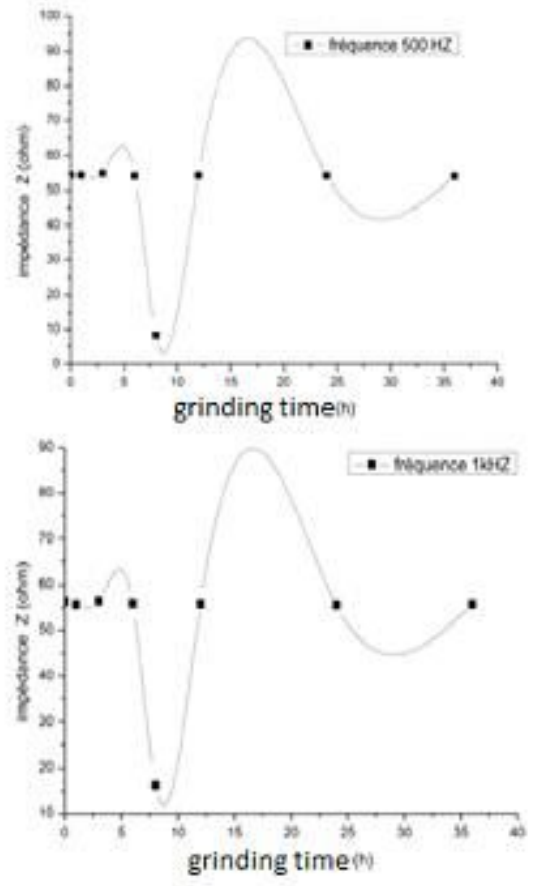

Fig 13. Variations of the impedance $\mathrm{Z}$ for $\left(\mathrm{Fe}_{65} \mathrm{C}_{35}\right)_{90} \mathrm{Cr}_{10}$

\section{Figure 9}

Figure 13 